\title{
Prosumer centric digital energy ecosystem framework
}

\author{
Kirsi Kotilainen \\ Tampere University of Technology \\ PL 527, FIN- 33101 Tampere
}

kirsi.kotilainen@tut.fi

\author{
Matti Sommarberg, \\ Pertti Järventausta \\ Tampere University of Technology \\ PL 527, FIN- 33101 Tampere \\ matti.sommarberg@kalmarglobal.com
}

pertti.jarventausta@tut.fi

\author{
Pami Aalto \\ University of Tampere \\ FIN- 33014 Tampereen yliopisto \\ pami.aalto@uta.fi
}

\begin{abstract}
Climate change is putting pressure on governments, policy makers and international organizations to increase energy efficiency and move towards using renewable energy sources. To meet growing need for energy and at the same time comply with ecologic and economic demands, the energy market structure is slowly transitioning from a centralized system to more interactive and decentralized model based on Smart Grid technology in which also end users may play a role as prosumers i.e. as producers and consumers of energy. Different scenarios exist for the level of prosumer participation in the future flexible energy ecosystem. In this paper, we propose a framework for Prosumer centric Digital Energy Ecosystem based on Smart Grid technologies, decentralized energy production using renewable energy sources and complex network of new and incumbent actors, business models and processes.
\end{abstract}

CCS concepts

- Social and professional topics $\rightarrow$ Professional topics $\rightarrow$ Computing and business $\rightarrow$ Socio-technical systems

\section{Keywords}

Smart Grid; digital business ecosystem; prosumer; open innovation; user led innovation; co-creation

\section{INTRODUCTION - ENERGY MARKETS IN TRANSITION TOWARDS FLEXIBLE ENERGY SYSTEMS}

Energy systems globally are in a process of profound transformation due to requirement to dramatically reduce carbon emissions, improve energy efficiency and move to renewable energy sources. Energy production must be more flexible with intermittent generation and must allow for the optimized management of the production and consumption of electricity and heat. This necessitates new technology components and business models. Smart Grid technology introduces the required intelligence to the power grid and enables flexibility, allows close to real time pricing as well as bi-directional communication and energy flows between suppliers and consumers. Smart Grid has two main functions: an) enabler of energy-efficient and

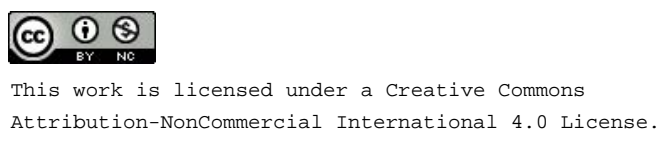

Copyright is held by the owner/author(s). MEDES'16, November 01-04, 2016, Biarritz, France ACM 978-1-4503-4267-4/16/11 ... \$15.00

DOI: http://dx.doi.org/10.1145/3012071.3012080 environmentally friendly energy market and b) critical infrastructure of society offering uninterrupted power supply [1]. At the same time commoditization, integration and affordability of information and communication technologies (ICT) have led to wide spread digitalization and convergence creating the open, global network connecting people, information, and thingsInternet of Things (IoT). Integration of the IoT into the energy system opens up a whole new way for management of the energy system. Internet of Energy (IoE) enables innovative ways of power distribution, energy storage, grid monitoring and communication as it enhances the transfer of energy and data bidirectionally.

In addition to new technologies, the business environment is changing and new actors emerge in the energy industry. Prosumers are consumers that also act as producers of energy. A prosumer can be an individual person as household level customer, a larger building (e.g. apartment building or shopping center), business entity like organization or a firm, or other kind of community. Prosumer may assume different level of activities that can vary from producing energy for own use to sharing excess energy through the grid and becoming an active participant in the energy industry. In this article we are exploring prosumer role as a value-creating actor in the developing energy ecosystem. Our research objectives are: RO1 - How should a digital energy ecosystem be defined; RO2 - How does the prosumer fit into the digital energy ecosystem?

\section{THEORY REVIEW}

\subsection{Socio-Technical Multi-Level Framework}

Industry transitions can be modeled using socio-technical multilevel framework [2] which is presented from the Smart Grid and energy ecosystem perspective in Figure 1.

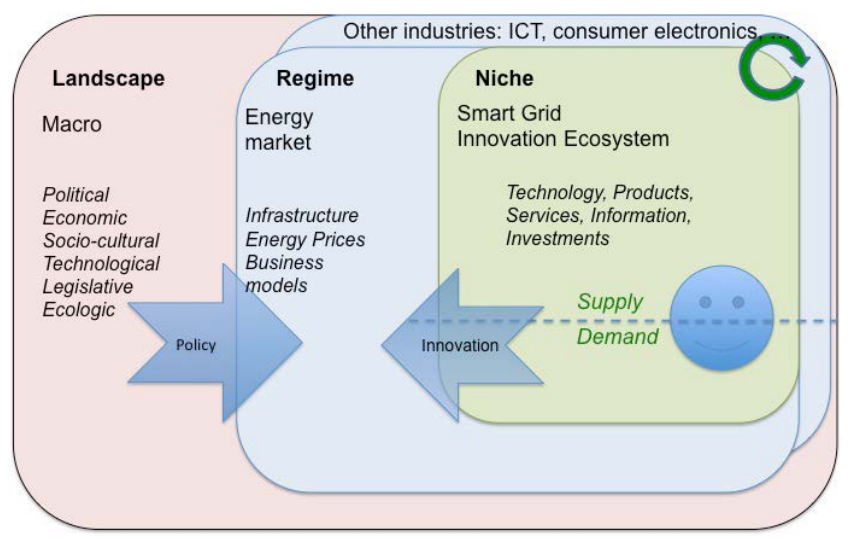

Figure 1. Socio-technical multilevel framework [3], [2]. 
The transition of energy industry is systemic, complex and takes place on different levels of society and technology. In the sociotechnical multilevel framework, the landscape represents macro level that steers (using policies and regulations) the energy regime evolution from centralized and monopolistic system towards more flexible and decentralized model based on renewable energy sources (RES). New technology development takes place at niche level where innovations add intelligence and robustness to the energy system. Smart Grid technology is largely based on ICT and enables new value creation opportunities and allows new players to enter the industry but also poses risks to the incumbent players that are tied to heavy investments in legacy infrastructure and established business models. This means that the energy industry dynamics is in flux.

\subsection{Changing Industry Dynamics}

Porter's [4] industry forces has been one of the seminal theories explaining industrial dynamics. In its core, competitive forces are driven by the power of suppliers and customers in the value chain. The out of industry dynamics originated from potential new entrants or new products or services.

Freeman's stakeholder view [5] already identifies e.g. environmentalists and consumer advocates as actors impacting firms and industries. Schumpeter [6] discussed earlier the prerequisite of socio-economic and political factors for technological innovation to achieve creative destruction. Many of the technological innovations where consumer becomes prosumer are not disruptive in a sense that Christensen [7] meant. Energy can be produced with established methods but the ability to connect production and consumption makes the difference. This creates analogy of the amount of connection and economic value that Metcalfe [8] coined in Internet context. One could argue that connectivity, or internet of energy (IoE), represents such a change of paradigm that Dosi [9] referred to as a source of discontinuity.

Natural inertia can explain whether an industry is conservative. Natural inertia means here long-time factors not dependent on any current or new actor wishing to introduce something new. Asset heavy industries like mining or energy plant construction possess logically such features. Developing a new mine, paper factory or nuclear power plant takes time. Planning and implementation is often shaped the availability of investment and regulatory requirements regarding possible competition issues and safety or environmental impact. Software industry is fundamentally different in this respect. The product is intangible and it can be scaled up globally in real time. The ICT industry has been pivotal in recent theories of industrial convergence [10].

The second category of inertia can be called perceived. It deals with the issues where fundamental source is beliefs - individual and collective. Current "correct way" of doing things can be called industry recipe [11] or dominant logic [12]. AirBnB, Momondo, Uber and many other software intensive start-ups have recently proved that the roles of customers and suppliers can change dynamically and fast growth can be initiated with an innovative approach. The incumbent actors in the energy regime have been traditionally slowing down the transition; heavy investments in energy infrastructure pose risks in the changing environment. Can ecosystem type of working methods be applied to the energy sector so that prosumers as a group could produce energy with such scale and speed that weighs when estimating the influence of the prosumer concept? Prosumer market or distributed electric networks are attractive for renewals and this has created a halo [13] effect. This makes it harder for incumbents not to participate.

\subsection{Ecosystems}

In a business ecosystem participating actors depend on each other for survival - and success. Moore defines business ecosystem as "an economic community supported by a foundation of interacting organizations and individuals." [14]. A digital ecosystem can be described as a self-organizing digital infrastructure for creating a digital environment for organizations that 'supports the cooperation, the knowledge sharing, the development of open and adaptive technologies and evolutionary business models' [15]. Chang and West [16] associate digital ecosystems and biological ecosystems by describing the digital ecosystem actors as biological, economic (organizations) and digital (digital platforms) species and propose that underlying technologies and services support the digital ecosystems.

Digital business ecosystem (DBE) combines both business ecosystem (economy) and digital ecosystem (digital representation of economy) [17]. According to World Economic Forum definition, the digital business ecosystem is: “... the space formed by the convergence of the media, telecoms and IT industries. It consists of users, companies, governments and civil society, as well as the infrastructure that enables digital interactions." DBEs are based on industry convergence (ICT technology) and openness (open innovation, open standards, open source software, open APIs) enabling innovation and value creation among the ecosystem actors.

Adner [18] describes innovation ecosystem as 'the collaborative arrangements through which firms combine their individual offerings into a coherent, customer-facing solution.' Wessner [19] considers innovation ecosystem as the national innovation system in which 'complex synergies between collective efforts among stakeholders bring innovation to the market'. Oh et al. [20] have summarized the characteristics of innovation ecosystem (when compared to other ecosystems) as being more explicitly systemic, based on digitalization and open innovation, having media appeal of 'innovation ecosystem' -term and accentuating the important role of 'niches'.

\subsection{User Centric Innovation Models}

Taking action to halt carbon emissions necessarily involves a number of parties in an attempt to make renewable energy ecosystem viable. There are several characteristics that are commonly linked to environmentally sustainable innovations: Large group of consumers need to adopt the innovation to make it successful [21]; Macro -level policy-induced financial and regulatory incentives are commonly used to accelerate the diffusion of environmentally important technology innovations; There may be willingness to pay more for environmental innovations due to environmental awareness [22]; Consumer behavioral change is required in order to fully take into use the environmental innovation [23]. E.g. changing one's behavior for environmental reasons has been one of the main arguments for e.g. taking into use Smart Metering [24]-[25].

To understand this type of networked innovation for example the traditional Triple Helix model of innovation focuses on the cooperation between universities, the industry and governments [35]. Quadruple Helix model expands the Triple Helix by adding the fourth helix: civil society [36]. Quintuple Helix is yet more comprehensive by adding the perspective of the 'natural environments of society' so that nature becomes recognized as an essential and equal element in the innovation and knowledge system [37]. 
From the process point of view, the traditional way of innovating is based on internal company processes, subcontracting and control whereas the new innovation modes increasingly rely on involving external stakeholders, including customers and even whole ecosystems, in the innovation process. Open innovation [26] can include various methods and levels of openness which can be divided into outside-in, inside-out and coupled. Examples of the outside-in process include for example crowdsourcing [27], and mass customization. Inside-out strategy conveys the locus of innovation to the market place and hopes to accelerate innovation development by external partiers. Coupled process combines elements of both outside-in (gain external knowledge) and insideout (bring ideas to markets) and is often called co-creation. Cocreation means bringing together different parties for example, a company and a group of customers, in order to jointly produce a mutually valued outcome [28]. Collaborating and co-creating with lead users is called user centric innovation or user led innovation [29]. It has been found that user led innovations seem to create commercially attractive solutions to the market place [30]. Strategic niche management [31] considers user centric innovation as part of the socio-technical transition. Kristensson et al. have developed strategies for successful user involvement in technology based services [32] that stress for instance taking into account that users are a heterogeneous group, mainly motivated through real life use cases and not necessarily technology savvy. Living labs [33] are often residential communities in which the people are observed in real life situations and engaged in cocreational activities. Smart City projects are another flourishing type of projects integrating many industries.

\section{DIGITAL ENERGY ECOSYSTEM PROPOSITIONAL FRAMEWORK}

To describe the digital energy ecosystem (RO1), we propose a prosumer centric Digital Energy Ecosystem Framework (pDEEF). The framework is presented in Figure 2.

\subsection{Actors}

According to the Quintuple innovation model, industry, citizens, regulators, academia and natural environment are all part of the innovation ecosystem. Socio-technical multilevel framework also assumes the importance of landscape level (macro environment) influence on innovation development taking place at the niche level. Regulators in our model represent the macro level and include for instance international organizations, European Union, national governments and municipalities. In addition, the Natural environment is considered as an integral part of the ecosystem in the energy production and consumption cycle.

In the energy markets there are incumbent energy industry actors e.g. distribution service operators (DSO), transmission service operators (TSO), Service Providers, Energy Retailers, installation and maintenance providers. There are also new actors in the including prosumers, aggregators, Smart Meter and home energy management system (HEMS) manufacturers, PV equipment manufactures, and storage manufacturers. Due to industry convergence, new entrants from other sectors are entering the energy market and include e.g. value added service (VAS) developers, end user equipment (mobile devices) manufacturers, ICT manufacturers, data management firms, independent software vendors (ISV) and telecom operators.

Digital actors (or platforms) in our framework contain hardware and software platforms i.e. smart meters, energy storage, HEMS, ICT infrastructure, ICT platforms, Smart Grid infrastructure, data hubs, web gateways, end user devices and user interfaces, development tool kits, sensors, home automation devices etc.

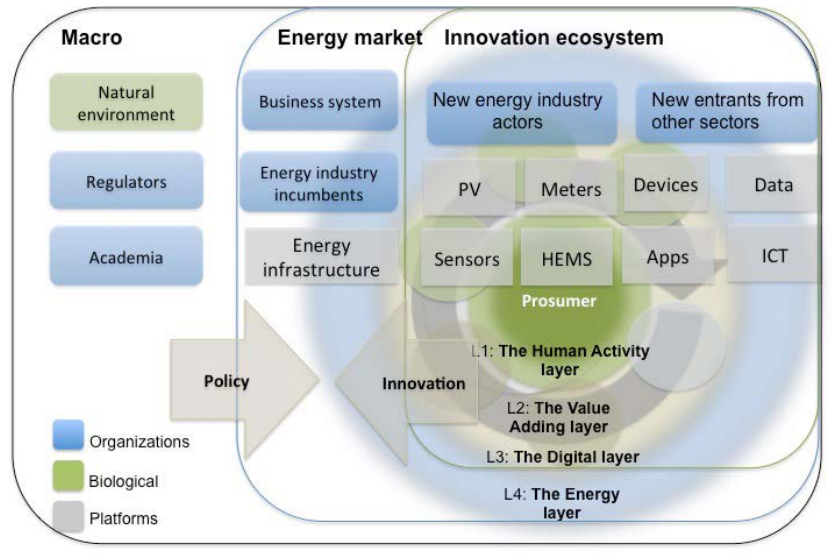

Figure 2. Prosumer centric Digital Energy Ecosystem Framework (pDEEF): actors and layers

\subsection{Layers}

We approach the question (RO2) 'how the prosumer fits into the digital energy ecosystem?' through outlining four layers for the digital energy ecosystem. The framework is based on simplified presentation of IoT layers (see e.g. [34]) completed with energy processes, value adding activity and human action.

L1: The Human Activity Layer - Prosumer, a new actor in the energy ecosystem can be either active or passive from ecosystem point-of-view. Most existing scenarios for prosumer 'activity' focus on energy efficiency and demand side management (DMS) [35] or, to in increasing amount, in prosumer community involvement [36]. An active prosumer can participate in energy production but could also get involved in innovation and value creation processes. Prosumers get access to innovation opportunities through various digital touch points including web, mobile devices (smart phones) and applications, user interfaces, web portals and billing system. The Human Activity Layer is closely interlinked to the next layer, L2: The Value Adding Layer.

L2: The Value Adding Layer - Process, activities and functions added applications and services. L2 consists of applications, processes and business models. Digital touch points connect the prosumers to core areas of energy market processes related to technology enablers, energy generation, business models, data monitoring, data analytics and value added services. The prosumer will have touch points to various aspects of physical and financial energy flows. Using digital tools (crowdsourcing platforms, virtual co-creation environments, toolkits, smart phones, web interface) the prosumers are able to contribute (ideas, feedback, development) to building innovative solutions on top of the digital platforms in the ecosystem (smart metering platforms, HEMS platforms, data platforms etc.). L2 is opened further in Figure 3.

L3: The Digital Layer - ICT infrastructure, Fog computing, Cloud computing and Big data. The digital layer collects, transfers, stores and manages data from various sensors, home automation devices, energy generation equipment (PV, wind), local storage, electric vehicles, smart metering etc. Digital layer can be seen as an Internet of Things (IoT) stack (see e.g. [34]). IoT and digital architectures are already well understood and defined; our model is based on established concepts (see e.g. [37], [38]). 


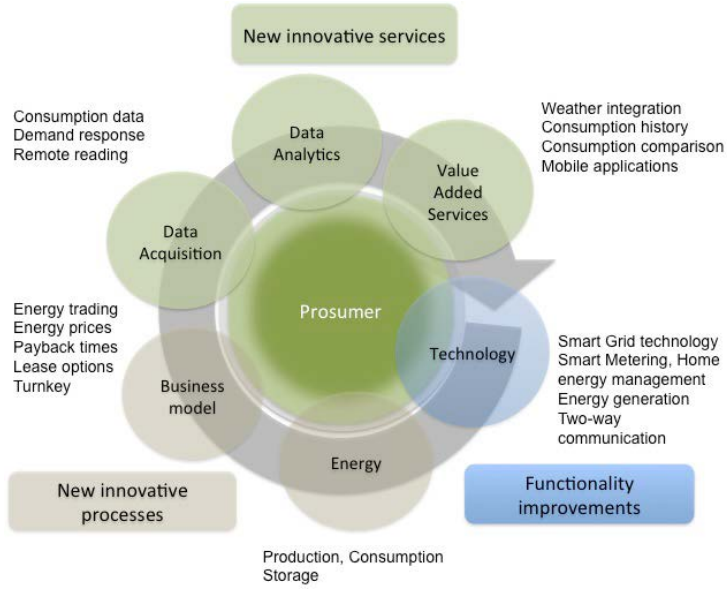

Figure 3. The Value Adding layer

L4: The Energy Layer - Energy production, transmission, distribution, consumption. Key components of the energy process are generation, transmission, distribution and demand. In terms of physical process, energy is generated centrally in large scale power plants (nuclear, hydro, coal, thermal) and solar and wind farms or/and de-centrally using distributed energy resources (DER) based on renewable energy resources (RES), such as photovoltaic (PV) or wind. High voltage transmission is managed by infrastructure operated by transmission system operators (TSO) as a monopolistic system. The TSOs are responsible for coordinating the supply and demand for electricity in wholesale market, take care of security of system and also handle crossborder trade between countries. Distribution system operators (DSO) carry the electricity from the transmission to individual consumers. Small-scale distribution is connecting to the grids and amount of bi-directional information and power flow is increasing rapidly. In the new system, DSOs will be in key role in managing the data and will have to deal with e.g. privacy requirements. Demand for energy depends on various aspects in the sociotechnical and economic system. Energy demand side management attempts to bring energy supply and demand closer together through various methods including energy efficiency measures, demand response (DR) and dynamic demand. Business process, or financial process point of view, the energy market is operated based on wholesale and retail principles.

Table 1. Barriers for prosumption

\section{BARRIER}

Lack of information on energy production

benefits

Regulatory barriers that pose limitations, increase complexity and involve bureaucracy

Resistance from incumbent energy market actors due to concerns over new competition, lack of predictability and controllability, risks associated to the balancing responsibility and investments in legacy infrastructure

Lack of incentives due to low electricity prices and unclear business models

Limited openness of technology vendors reducing end user participation in testing, feedback and co-creation of new solutions Economic issues e.g. high investment cost for energy production equipment

Privacy and security concerns over data usage and energy quality
Despite the current atmosphere being fertile for citizen participation, there are also obstacles that may slow down the end user participation in the digital energy ecosystem; some of these barriers [39], [40] are listed in Table 1.

\section{CONCLUSIONS}

We have introduced a propositional prosumer centric Digital Energy Ecosystem Framework (pDEEF) in order to increase comprehension on prosumer role in the future energy ecosystem. The framework was built based on deducting theoretical premises for the systemic nature of energy ecosystem and will require further validation through empirical testing. Prosumer as participant in the ecosystem value co-creation is currently an under-researched area and further studies in evaluating the innovation aspects of prosumption could help to build better understanding of the value creation potential in the energy ecosystem. Our framework exemplifies the needed multidisciplinary research combining innovation ecosystem, end user role, complex industry transitions and new technology platforms together. The framework also considers systemic nature of the energy markets as socio-technical change (including multistakeholder view) and builds links between different types of processes (energy process, digitalization process, value creation process and human activity) that are all relevant for the ecosystem success.

\section{REFERENCES}

[1] P. Järventausta, "Smart Grids with large scale implementation of Automatic Meter Reading - Experiences from Finland.," in the Handbook of Clean Energy Systems, John Wiley \& Sons, Ltd, 2015.

[2] F. W. Geels, "The multi-level perspective on sustainability transitions: Responses to seven criticisms," Environ. Innov. Soc. Transitions, vol. 1, no. 1, pp. 24-40, 2011.

[3] K. Kotilainen, S. Mäkinen, P. Järventausta, A. Rautiainen, and J. Markkula, "The role of residential prosumers initiating the energy innovation ecosystem to future flexible energy system.," in Proceedings or European Energy Markets Conference 2016, 2016.

[4] M. E. Porter, "How competitive forces shape strategy," Harv. Bus. Rev., no. April-March, pp. 137-144, 1979.

[5] E. R. Freeman, Strategic Management: A Stakeholder Approach. 1984.

[6] J. A. Schumpeter, Capitalism, Socialism and Democracy. HarperCollins Publishers, New York, USA, 1942.

[7] C. M. Christensen, The Innovators Dilemma. HarperCollins, New York, USA, 1997.

[8] R. Metcalfe, "Metcalfe's Law Revisited after 40 Years of Ethernet," Computer, vol. 46, no. 12, pp. 26-31, 2013.

[9] G. Dosi, "Technological Paradigms and Technological Trajectories: A Suggested Interpretation of the Determinants and Directions of Technical Change," Res. Policy, vol. 11, no. 3, pp. 147-162, 1982.

[10] F. Hacklin, C. Marxt, and F. Fahmi, "An Evolutionary Perspective on Convergence: Including a Stage Model of Inter-Industry Innovation," Int. J. Technol., vol. 49, no. 1-3, pp. 220-249, 2010.

[11] J.-C. Spender, Industry Recipes, An Enquiry into Nature and Sources of Managerial Judgement. ournal of the Operational Research Society, 1989. 
[12] C. K. Prahalad and R. A. Bettis, "The Dominant Logic: a New Linkage Between Diversity and Performance," Strateg. Manag. J., vol. 7, no. 6, pp. 485-501, 1986.

[13] P. Rosenzweig, The Halo Effect. Free Press, New York, USA, 2007.

[14] J. Moore, The Death of Competition - Leadership and Strategy in the Age of Business Ecosystems. Wiley, 1996.

[15] "Digital Ecosystems," Directorate General Information Society and Media, European Commission. [Online]. Available: http://www.digital-ecosystems.org.

[16] E. Chang and M. West, "DIGITAL ECOSYSTEMS A NEXT GENERATION OF THE COLLABORATIVE ENVIRONMENT," in Proceedings of iiWAS2006, 2006, pp. 3-23.

[17] F. Nachira, P. Dini, and A. Nicolai, "Network of Digital Ecosystems for Europe: Roots , Processes and Perspectives," pp. 5-24.

[18] R. Adner, "Match Your Innovation Strategy Innovation to YourEcosystem," Harv. Bus. Rev., vol. 84, no. 4, pp. 98 107, 2006.

[19] C. Wessner, Entrepreneurship and the innovation ecosystem policy lessons from the United States. 2005.

[20] D. S. Oh, F. Phillips, S. Park, and E. Lee, "Innovation ecosystems: A critical examination," Technovation, vol. 54, pp. 1-6, 2014

[21] S. H. Schwartz, "Normative Influences on Altruism.," in Advances in Experimental Social Psychology, vol. 10, L. Berkowitz, Ed. Academic Press, New York, 1977, pp. 221279.

[22] M. Laroche, J. Bergeron, and G. Barbaro-Forleo, "Targeting consumers who are willing to pay more for environmentally friendly products," J. Consum. Mark., vol. 18, no. 6, pp. 503-520, 2001.

[23] T. Hargreaves, "Practice-ing behaviour change: Applying social practice theory to pro-environmental behaviour change," J. Consum. Cult., vol. 11, no. 1, pp. 79-99, 2011.

[24] J. Burgess and M. Nye, "Re-materialising energy use through transparent monitoring systems," Energy Policy, vol. 36, no. 12, pp. 4454-4459, 2008.

[25] S. Darby, "The effectiveness of feedback on energy consumption. A Review for DEFRA of the Literature on Metering, Billing and direct Displays," Environ. Chang. Inst. Univ. Oxford, vol. 22, no. April, pp. 1-21, 2006.

[26] E. Enkel, O. Gassmann, and H. Chesbrough, "Open R\&D and open innovation: Exploring the phenomenon," $R D$
Manag., vol. 39, no. 4, pp. 311-316, 2009.

[27] J. Howe, "The Rise of Crowdsourcing," Wired Mag., vol. 14, no. 6, pp. 1-5, 2006.

[28] C. K. Prahalad and V. Ramaswamy, "co-Creating Unique Value With Customes," Strateg. Leadersh., p. 32,3, 2004.

[29] E. Von Hippel, "Lead users: a source of novel product concepts.," Manage. Sci., vol. 32, no. 7, pp. 791-805, 1986.

[30] E. Von Hippel, "Democratizing innovation," Journal für Betriebswirtschaft, vol. 55, no. 1. p. 63-78., 2005.

[31] M. Weber, R. Hoogma, B. Lane, and J. W. Schot, Experimenting with sustainable transport innovations: a workbook for strategic Niche management. Seville/Enschede: Universiteit Twente., 1999.

[32] P. Kristensson, J. Matthing, and N. Johansson, "Key strategies for the successful involvement of customers in the co-creation of new technology-based services," Int. J. Serv. Ind. Manag., vol. 2, no. 2, pp. 49-65, 1991.

[33] M. Pallot, B. Trousse, B. Senach, and D. Scapin, "Living Lab Research Landscape: From User Centred Design and User Experience towards User Cocreation," Technol. Innov. Manag. Rev., vol. 1, pp. 19-25, 2010.

[34] M. Kavis, "Investor's Guide to IoT - Part 1: Understanding The Ecosystem," Cloud Technology Partners, 2016. http://www.cloudtp.com/2016/02/25/investors-guide-to-iotpart-1-understanding-the-ecosystem/.

[35] S. Karnouskos, "Demand Side Management via prosumer interactions in a smart city energy marketplace," IEEE PES Innov. Smart Grid Technol. Conf. Eur., pp. 1-7, 2011.

[36] A. J. D. Rathnayaka, V. M. Potdar, and S. J. Kuruppu, “An innovative approach to manage prosumers in Smart Grid," 2011 World Congr. Sustain. Technol., pp. 141-146, 2011.

[37] O. Mazhelis and P. Tyrvainen, "A framework for evaluating Internet-of-Things platforms: Application provider viewpoint," Internet Things (WF-IoT), 2014 IEEE World Forum, no. February 2011, pp. 147-152, 2014.

[38] J. Gubbi, R. Buyya, and S. Marusic, "Internet of Things ( IoT ): A Vision , Architectural Elements , and Future Directions," Futur. Gener. Comput. Syst., vol. 29, no. 7, pp. 1645-1660, 2013.

[39] D. Six, W. Fritz, and K. Kessels, "Potential Barriers and Solutions for Active Demand: a Qualitative Analysis," in i_SUP, 2010,pp. 1-7.

[40] IEA-RETD, "Residential Prosumers - Drivers and Policy Options (RE-Prosumers)," 2014. 